\title{
CORRUPÇÃO VERSUS PRODUÇÃO: UMA APLICAÇÃO DO MODELO SOLOW AMPLIADO
}

\author{
CORRUPTION VERSUS PRODUCTION: AN APPLICATION \\ OF THE EXTENDED SOLOW MODEL
}

Sergiany da Silva Lima ${ }^{1}$

Lívia Rodrigues de Lima Pires ${ }^{2}$

Fernando José Nogueira ${ }^{3}$

1

Doutorado em Teoria Econômica pela Universidade Federal Fluminense (2017) com período sanduíche na Universidad Nacional Del Sur (UNS). Possui graduação em Economia pela Universidade Regional do Cariri (2006), mestrado em Economia Rural pela Universidade Federal do Ceará (2008).

2

Mestre em economia pela Universidade Federal de Pernambuco (2015) e graduada em Bacharelado em Ciências Econômicas pela Universidade Federal Rural de Pernambuco (2011) Atualmente é Professora Adjunta da Universidade Federal Rural de Pernambuco. 3

Graduado em economia pela UFRPE/UAST.
RESUMO: Essa pesquisa tem como objetivo medir o efeito da corrupção sobre o PIB per capita mundial, baseado nas hipóteses das teorias revisionista e rent-seeking. Para a teoria revisionista, a corrupção imprime velocidade protocolar aos investimentos, enquanto que para as teorias rent-seeking e da eficiência institucional, a corrupção gera custos adicionais gerando incertezas ao desenvolvimento econômico. Diante disso, o modelo empírico explora uma terceira hipótese possível através de uma relação não linear do efeito da corrupção sobre a produção agregada. O referido modelo explicita a proxy de corrupção usando a função de produção do modelo de Solow ampliado. A equação é estimada usando regressões com dados em painel no período de 2012 a 2017. O resultado sugere que a ausência de corrupção aumenta a produção agregada, mas a uma taxa decrescente. Ou seja, sugere que exista uma taxa ótima de corrupção capaz de estimular os investimentos sem comprometer a confiança institucional.

palavras-chave: Crescimento Econômico, Produção Agregada, Corrupção.

ABSTRACT: This research aims to measure the effect of corruption on world per capita GDP, based on the assumptions of revisionist and rent-seeking theories. For the revisionist theory, corruption imposes speed on investments, while for rent-seeking theories and institutional efficiency, corruption generates additional costs generating uncertainties for economic development. Thus, the empirical model explores a third possible hypothesis through a non-linear relation of the effect of corruption on aggregate production. This model explains the corruption proxy using the extended production function of the Solow's model. The equation is estimated using regressions with panel for the period 2012 to 2017. The main result suggests that the absence of corruption increases aggregate production but at a decreasing rate. Thus, the results suggest that there is an optimum rate of corruption that can stimulate investments without compromising institutional trust.

KEYwORDs: Economic Growth, Aggregate Production, Corruption. 


\section{INTRODUÇÃO}

A corrupção é um fenômeno que ocorre em todos os países, alguns com maior intensidade do que em outros, e para explicar essa prática, Del Monte e Papagni (2001) dividiram-na em três causas: econômicas, políticas e culturais. As causas econômicas dão-se na obtenção de interesses financeiros pessoais. As causas políticas são explicadas pelo abuso de poder com o objetivo de obter votos, para isso são encaminhados recursos públicos para as regiões de sua base eleitoral. As causas culturais da corrupção estão associadas às questões religiosas e crenças predominantes das regiões, comportamento social e influência da comunicação.

Os principais indicadores que medem o nível de corrupção no mundo são o Índice de Corrupção Percebida (ICP) mensurado pela organização não governamental Transparency International e o Worldwide Governance Indicator (WGI) produzido pelo Bando Mundial. Entre os anos de 1998 a 2008, a corrupção do Brasil era considerada crítica, quando comparado o seu ICP a países menos corruptos como a Dinamarca, e a países altamente corruptos, como a Nigéria (SOBRAL, 2014). A situação econômica do Brasil se mostra coerente com a premissa de que a percepção de corrupção inibe o desempenho econômico dos países (TREISMAN, 2000 apud SOBRAL, 2014). Em uma análise sobre os países latino-americanos, segundo a percepção de corrupção em 2000, o Chile e a Costa Rica mostraram-se acima da média mundial de 48 com ICP de 74 e 54, respectivamente. Ao todo, são analisados 90 países segundo o nível de percepção da corrupção e o resultado sugere que há uma correlação negativa entre as variáveis de ICP e PIB per capita (ABRAMO, 2000). A percepção de corrupção na África reflete negativamente em áreas como: crescimento econômico, pobreza, distribuição de renda, investimento, educação e saúde pública. Na década de 1990, cerca de 148 bilhões de dólares foram transferidos para contas no exterior (paraísos fiscais) de agentes públicos. No ranking dos países mais corruptos do mundo, Moçambique ocupa a $119^{\underline{0}}$ posição em 175 países analisados no ano de 2014. O ICP de Moçambique é de 31. De acordo com a Policy and Institutional Assessment (PIA), Moçambique se equipara a Serra Leoa, cuja classificação corresponde a $20^{\underline{a}}$ posição entre os 20 países mais corruptos do continente (CENTRO DE INTEGRIDADE PÚBLICA, 2016). A Nigéria é o país mais populoso da África com uma população estimada em torno de 180 milhões de habitantes. Sua economia é baseada na exploração dos recursos naturais, agricultura tradicional e comércio (NIGERIA/Federal Republic of Nigeria, 2017). O país é marcado por problemas estruturais como pobreza, alto crescimento populacional, baixo desenvolvimento e corrupção, agravadas desde a colonização (CIERCO e BELO, 2016). O status de corrupção da Nigéria o classificou como um país altamente corrupto em 2014. O crescimento de 2,7 do seu ICP em 2014 levou o país para a $136^{\circ}$ posição entre os 175 países analisados. A corrupção se manifesta principalmente através da 
lavagem de dinheiro, subornos, fraudes e má administração no serviço público. Todos esses fatos influenciam o baixo desenvolvimento do país. No ano de 2016, a Nigéria obteve um índice um pouco maior do que 28 , ficando na $136^{\underline{a}}$ posição entre os 176 países. Em contraposição, a Dinamarca é um país localizado no norte da Europa, com população estimada em 5,6 milhões de habitantes, no ano de 2014. Mesmo sendo considerado um país pequeno, sua economia tem como base a indústria tecnológica e finanças (DENMARK, 2017). A ética e a transparência no setor público são tradições na Dinamarca, além disso, as leis dinamarquesas em relação à corrupção são rígidas, como apresenta o Relatório Anticorrupção da União Europeia (2014). Em 2013, o país alterou a legislação destinada a reforçar a prevenção, a investigação e o julgamento de casos relacionados com crimes econômicos, além do aumento das penas para esse tipo de crime. As providências anticorrupção podem ser comprovadas pelo ICP, a nota do país foi de 92 e 90 nos anos de 2014 e 2016, respectivamente. A Dinamarca ocupa o $1^{\underline{o}}$ lugar e é considerado o país menos corrupto do mundo nesses dois anos.

A Itália conta com uma população média de 60 milhões de habitantes. Considerada uma das maiores economias da Europa, sua matriz econômica, basicamente, gira em torno da agricultura, finanças, indústrias e turismo (WORLD DATA BANK, 2017). Nos anos de 1990, houve uma queda significativa no PIB italiano, quando descobertos recorrentes casos de corrupção. Esse fato desencadeou a operação Mani Pulite (Mãos Limpas), cujo propósito era investigar os casos de corrupção envolvendo licitações e abuso de poder entre políticos e partidos da época. Como resultado dessa investigação, foram identificados legisladores, burocratas e empresários envolvidos em vários esquemas. Esses escândalos encerraram o fim da chamada Primeira República Italiana (FIORINO; GALLI; PETRARCA,2012).

Mesmo com todos esses casos relatados pela literatura e apoiados no relatório de dados da Transparency International, existem duas correntes teóricas antagônicas sobre os efeitos da corrupção sobre a produção econômica. A primeira delas assume que a corrupção é o custo do desenvolvimento econômico, por essa razão acredita-se que a corrupção afete positivamente o crescimento econômico por destravar processos burocráticos e demorados. Esse primeiro grupo é conhecido como a corrente revisionista, cujos representantes são Leff (1964), Huntington (1968), Nye (1967) e Bardhan (1997). A segunda corrente teórica, denominada rent-seeking, parece mais coerente com os dados da maior parte da literatura e do relatório da Transparency International, de que a corrupção influencia negativamente a produção agregada da economia. Nesse caso, a ausência da corrupção exerceria um efeito positivo sobre a produção. Os principais autores que compartilham essa visão do efeito negativo da corrupção sobre o crescimento são Mo (2001), Silva (1995) e Boll (2010).

Desse modo, com o intuito de entender qual é a relação entre corrupção e produção econômica, esse trabalho tem como objetivo testar 
os efeitos da corrupção sobre a produção econômica agregada, baseado nas premissas das teorias revisionista e rent-seeking. O teste empírico pode ser controlado para captar as duas informações antagônicas através de uma especificação não linear do efeito da corrupção sobre a produção agregada nacional, usando uma metodologia com dados em painel. A ideia de um painel de dados com os países do mundo para esse teste empírico no período recente de 2012 a 2017 se deve a dois motivos. Uma amostra com todos os países minimiza a existência de resultados viesados por casos excepcionais e individuais da história econômica e cultural de cada país. Depois, o período recente engloba os últimos casos de corrupção de grande impacto político e econômico que se deram principalmente nos países da América Latina.

\section{FUNDAMENTAÇÃO TEÓRICA}

Na literatura, alguns autores analisaram a relação entre corrupção e crescimento econômico. De acordo com Garcia (2003), há duas correntes teóricas com relação ao crescimento econômico e corrupção. A primeira delas se refere a corrente revisionista em que seus defensores garantem que em alguns casos a corrupção pode ser benéfica (LEFF, 1964; HUNTINGTON, 1968). A segunda corrente é intitulada de rent-seeking em que os autores defendem que esta relação dar-se de forma negativa (MO, 2001; CARRARO; FOCHEZATTO; HILLBRECHT, 2006; FIORINO; GALLI; PETRARCA, 2012).

\section{ETIMOLOGIA, CONCEITO E TIPICIDADE DA CORRUPÇÃO}

Segundo o projeto Transparência na Gestão Pública (2016), a corrupção já era abordada por filósofos como Platão e Aristóteles, durante os séculos V e IV a.C., respectivamente. Para esses filósofos, tal prática era mencionada quando não eram cumpridas as leis em troca de algo e pela ambição. Durante os séculos XV e XVIII, diversos filósofos abordaram o tema, entre eles, Maquiavel, Jean-Jacques Rousseau e Montesquieu, os quais propagaram que a corrupção tem um sentido crescente, primeiro alcança a sociedade e logo atinge entidades governamentais.

A palavra corrupção tem origem latina corruptione. Esta palavra denota decomposição, putrefação, depravação, desmoralização, sedução e suborno. A palavra corrupção associa-se a atos ilegais em um ambiente político onde há abuso de poder para a obtenção de privilégios ou propinas. A corrupção tem muitos sentidos, mas para um sentido comum, ela envolve uma relação entre dois indivíduos ou mais (corruptos e corruptores) e este vínculo acarreta em transferências de rendas de forma ilegal. A corrupção é um ato ilegal e ilegítimo, tornando-se assim uma prática criminosa. Sua extensão compreende tanto o político, que transfere renda na forma de propinas visando o interesse particular, quanto o burocrata que recebe suborno em troca de favores (SILVA, 1995). 
A corrupção como um crime econômico por ser compreendida como venda de propriedades do governo por parte dos servidores visando benefícios pessoais, podendo haver custos para o desenvolvimento econômico. Essa mesma ideia é apresentada no relatório da Federação das Indústrias do Estado de São Paulo (FIESP, 2010), onde a corrupção pode ser entendida como um desvio dos deveres associados a um cargo público para o benefício privado (SOBRAL et al., 2015).

Para que uma prática corrupta seja realizada, sempre haverá corruptos dos dois lados (o corruptor e o corrompido), ou seja, ambos são criminosos e culpados pela prática ilegal, em que a sociedade padecerá do ato. Nesse sentido, o agente corruptor age de forma racional tendo consciência que sua ação pode acarretar tanto em benefícios próprios como em punições e quando comparado a um crime comum, onde só existe um criminoso, no caso da corrupção, ambos os participantes são criminosos (ROSE-ACKEMAN, 1975 apud SOBRAL, 2014).

Com o intuito de medir a corrupção em números, a organização não governamental Transparency International (TI) criou em 1995 o Índice de Corrupção Percebida (ICP), com o intuito de investigar o nível de corrupção percebido nos países. Em 1996, um novo indicador foi apresentado pelo Banco Mundial, o Worldwide Governance Indicators (WGI), composto por seis indicadores que buscavam medir a qualidade da governança em 215 países, o respeito aos cidadãos, políticas e interações econômicas usadas na comparação entre países. O índice é obtido a partir de entrevistas com empresas e com a população, e os dados são publicados, anualmente, no site do Banco Mundial (WGI, 2017).

Com relação aos posicionamentos teóricos das causas e consequências da corrupção, na teoria revisionista o agente é sujeito passivo recebendo suborno. Na teoria rent-seeking, ou caçadores de renda, os agentes agem como sujeito ativo na busca de brechas para a obtenção de recursos ilícitos. Existe ainda uma outra visão que reforça a rent-seeking, abordando a relação entre eficiência, crescimento, desenvolvimento e corrupção. Ela afirma que a corrupção afeta as instituições, gerando incertezas e inibindo novos investimentos nos países, pois os custos da corrupção diminuem o retorno esperado dos investimentos (SHLEIFER e VISHNY, 1993).

\section{TEORIA REVISIONISTA DA CORRUPÇÃO}

Essa corrente teórica das causas e efeitos da corrupção parte da premissa de que a agilidade das atividades econômicas em estruturas burocráticas pressupõe a existência da propina ou suborno por representantes governamentais e agentes privados. O mecanismo da propina funciona através da transferência de renda ilegal dentro da sociedade visando vantagens individuais. Com a intenção de maximizar suas utilidades, os agentes vendem seus serviços desempenhados dentro das suas próprias funções, sejam públicas ou privadas. A venda ocorre desde que seja satisfatório para ambos os agentes, ou seja, que maximize o bem-estar de todos os envolvidos (SILVA, 2004). 
Um dos primeiros autores a analisar a relação corrupção e crescimento econômico foi Leff (1964), como resultado mostrou uma relação positiva e constatou que o suborno seria uma forma de alavancar o crescimento econômico, agilizando protocolos burocráticos. Para ele, a corrupção em países em desenvolvimento pode ser benéfica quando a mesma soluciona casos burocráticos por meio de propinas para empreendedores dispostos a pagar. Enquanto que Nye (1967) analisou o custo da corrupção no desenvolvimento político e identificou que a corrupção tem um efeito negativo caso o dinheiro seja aplicado em paraísos fiscais, porém, caso o recurso seja mantido no país de origem, o custo dessa corrupção não seria tão impactante no desenvolvimento político, pois, o dinheiro seria aplicado na economia nacional. Para Huntington (1968), a relação positiva dava-se em países em desenvolvimento que passam por constantes mudanças em seu sistema econômico por meio de sua modernização. Para esta afirmação, Huntington explica que o crescimento econômico não consegue acompanhar esse ritmo.

Silva (1995) mostra que a corrupção tem grandes impactos sobre o desenvolvimento, como por exemplo, transferências de renda e o subdesenvolvimento econômico e social. Já Mo (2001), relatou que as atividades inovadoras são as que mais se prejudicam com a corrupção, pois, além de não terem incentivos dependem de algumas funções do governo, como, alíquotas para importação e licenças, provocando assim uma redução de investimento privado e, consequentemente, acarreta uma queda no volume de estoque produzido.

A burocracia, tanto pública quanto privada, é comandada por uma hierarquia cuja função é resolver os problemas da melhor forma, no qual os agentes públicos agem de acordo com suas funções e respeitam as normas burocráticas. Com o poder de resolver certas funções, os burocratas tendem a defender interesses próprios e, agindo corruptamente, dentro dos seus interesses pessoais, disponibilizam informações que os beneficiam. Em uma economia com governo, este acaba consumindo uma grande parcela de bens e serviços ofertados pelo mercado, aplicando-os à população. Com a entrada do governo na economia, são identificadas falhas de mercado, brechas que facilitam a inserção da propina por meios de licitações ou leilões, por exemplo. Grandes investimentos providos pelo governo que envolvem altas quantias de dinheiro público são manipulados por agentes públicos e privados para fins próprios, evidenciando falhas de mercado e falta de controle que causam abertura para a propina e para a corrupção (SILVA, 1995).

\section{TEORIA RENT-SEEKING DA CORRUPÇÃO}

Baseado no princípio subjacente a teoria rent-seeking, os agentes econômicos visam à obtenção de lucros econômicos positivos, causando imperfeições institucionais. Esses agentes buscam maximizar as suas rendas podendo ultrapassar as leis da sociedade, sejam essas 
leis econômicas ou sociais, essa prática é chamada caçadores de renda. Os custos dessa prática são sentidos principalmente pela sociedade, ocasionando um custo de oportunidade e social. Essa prática ocorre quando os monopolistas alocam recursos produtivos em atividades ligadas ao próprio monopólio e em seus interesses próprios através de propagandas e lobbying. Nos países em desenvolvimento, como o Brasil, essa prática é bastante comum entre os agentes públicos de programas de desenvolvimento sociais que recebem propinas quando a demanda é alta para esses programas.

Na corrente rent-seeking, Mo (2001) identifica a relação corrupção e crescimento econômico de forma negativa quase proporcional, em que $1 \%$ de aumento da corrupção resultaria em uma queda de $0,72 \%$ no crescimento econômico. Este autor identificou que essa redução pode afetar o investimento, o capital humano e estabilidade política. Carraro, Fochezatto e Hillbrecht (2006) analisaram o impacto da corrupção sobre o crescimento econômico do Brasil para o período 1994-1998 e comprovaram que no curto prazo, o crescimento econômico com corrupção é maléfico por ser um crescimento econômico não-sustentável e logo, acarretará para a população, no longo prazo, elevação da taxa de juros penalizando o consumo das famílias.

Por fim, Fiorino, Galli e Petrarca (2012) comprovaram uma correlação negativa entre a corrupção e o crescimento econômico na Itália no período de 1980 a 2004, assim como Del Monte e Papagni (2001), ambos investigaram a relação e os casos de corrupção na Itália e puderam concluir que as práticas corruptas partiram de agentes do governo envolvendo as despesas públicas e os burocratas. Identificaram ainda a prática da diferenciação de renda para o norte e sul do país, pois o sul da Itália apresenta um maior desenvolvimento e políticas públicas de combate à criminalidade e a corrupção. $\mathrm{O}$ modelo de Del Monte e Papagni (2001) apresentou dois efeitos negativos distintos da corrupção sobre o crescimento econômico no período analisado: o investimento privado e a eficiência das despesas com investimento público, caso as políticas públicas solucionem esses dois fatores, a economia tende a crescer.

Uma visão complementar sobre as causas e consequências da corrupção pressupõem que existe uma relação entre eficiência, crescimento, desenvolvimento e corrupção. O tema decorre da relação entre instituições, corrupção e a sua relação com o crescimento econômico. Para que ocorra a corrupção, deverá haver um custo, tanto em relação à propina, quanto em relação à compra do silêncio pela prática ilícita. A corrupção impacta no crescimento econômico de um país através da diminuição dos investimentos externos, onde empresas e investidores estrangeiros optam por não investir em países onde os índices de corrupção, por meio do governo e de setores privados, sejam elevados, uma vez que o retorno do capital empregado torna-se incerto, transferindo o investimento para países onde os índices de corrupção são menores (SILVA, 2004). 
As empresas, ao investirem em países corruptos, incorporam os valores das propinas ao cálculo dos seus custos operacionais e de implantação, algo que pode reduzir a competitividade das empresas locais em relação a outras situadas em países menos corruptos. Shleifer e Vishny (1993) confirmam essa visão citando o caso da Rússia pós-comunista, em que poucas empresas estrangeiras têm interesse em investir, dado o grau corrupção russo.

\section{METODOLOGIA}

Para estimar o efeito da corrupção sobre a produção econômica agregada é utilizado um modelo não linear na variável de corrupção, com dados em painel. O objetivo é captar resultados empíricos baseados nas premissas da teoria revisionista e rent-seeking. A teoria revisionista assume que a corrupção contribui para o avanço econômico devido a vantagens ilícitas protocolares que emperram os investimentos. A teoria rent-seeking faz uma avaliação do efeito negativo da corrupção sobre o nível de produção econômica, por entender que a corrupção torna ineficientes os investimentos.

Pensando individualmente nessas relações causais das suposições teóricas, onde a existência de um efeito rejeita a existência do outro, a especificação linear nas variáveis e parâmetros pode exibir resultados viesados. Isso porque, ambos os efeitos da corrupção podem estar afetando o nível de produção global no tempo recente. Por essa razão, a especificação não linear da corrupção sobre a produção agregada mundial se apresenta como mais adequada para o teste empírico. Além disso, para não superestimar esse efeito, optou-se por incluir a variável proxy de corrupção na função de produção agregada do modelo de Solow ampliado com capital humano.

\section{MODELO ECONÔMICO}

Utilizando como referência a função de produção do modelo de Solow ampliado com capital humano, é possível explicitar o efeito da corrupção sobre a produção, a priori vinculado a escalar tecnológica da função (A). Ao fazer isso, melhora-se o modelo reduzindo o distúrbio aleatório da função de produção empírica. Baseado no modelo de produção da função aumentada disponível em Mankiw et al. (1992), modelou-se a escalar tecnológica para uma função quadrática da corrupção.

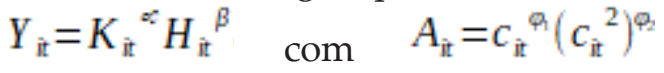

Em que $Y$ é a produção agregada; $K$ o estoque de capital físico; 
$H$ o estoque de capital humano; $L$ o número de trabalhadores; $A$ é a escalar tecnológica da função; e $c$ é o nível de corrupção. Os parâmetros refletem o retorno decrescente do estoque de capital sobre a produção agregada, já os parâmetros definem a relação causal da corrupção sobre a produção. As elasticidades e do estoque de capital físico e capital humano, assim como a elasticidade da corrupção sobre a produção agregada são definidas através do logaritmo da Equação 1 per capita.

$$
\ln y_{\mathrm{it}}=\propto \ln k_{\mathrm{it}}+\beta \ln h_{\mathrm{it}}+\gamma_{1} \ln c_{\mathrm{it}}+\gamma_{2} \ln c_{\mathrm{it}}^{2}
$$

Se $\gamma_{1}<0 e \gamma_{2}=0$, a relação é revisionista, o efeito da ausência de corrupção é negativo;

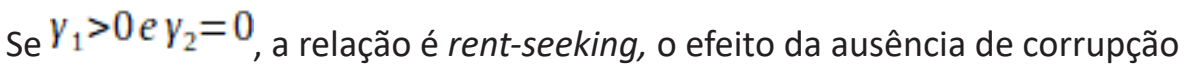
é positivo;

Se $\gamma_{1}>0 e \gamma_{2}<0$, a relação é revisionista e rent-seeking, o efeito da ausência de corrupção é positivo e decrescente.

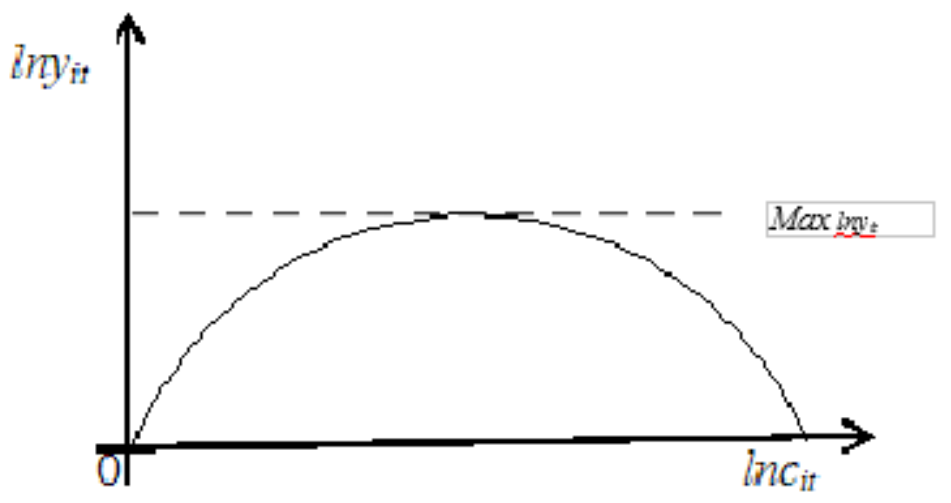

FIGURA 1: Relação esperada da terceira hipótese do modelo empírico

\section{MODELO EMPÍRICO}

A regressão empírica é estimada através dos modelos de dados em painel, usando os estimadores de dados empilhados (pooled), efeito fixo e aleatório. O estimador pooled admite que não haja distinção entre o grupo de indivíduos e que as variáveis explicativas não são correlacionadas com o resíduo. O estimador de efeito fixo controla fatores individuais que não variam no tempo, ou seja, trata variáveis aleatórias não observadas correlacionadas com os regressores. O estimador de efeito aleatório assume que esses fatores individuais são aleatórios.

$$
\ln y_{\mathrm{it}}=\beta_{0}+\beta_{1} \ln k_{\mathrm{it}}+\beta_{2} \ln h_{\mathrm{it}}+\beta_{3} \ln c_{\mathrm{it}}+\beta_{4} \ln c_{\mathrm{it}}{ }^{2}+\mu_{\mathrm{i}}+\gamma_{\mathrm{t}}+u_{\mathrm{it}}
$$

$O$ melhor estimador, entre o efeito fixo e aleatório é determinado através do teste de Hausman, cuja hipótese nula é aceitar o estimador de efeito aleatório. O teste de Chow determina a escolha entre o modelo Pooled com dados empilhados e o de efeito fixo com hipótese nula de aceitar o modelo restrito (pooled). O teste $\mathrm{lm}$ de Breush-Pagan é utilizado na escolha entre os modelos Pooled e de efeito aleatório. De maneira 
semelhante, sua hipótese nula é aceitar o modelo Pooled.

\section{APRESENTAÇÃO DAS VARIÁVEIS E FONTE DOS DADOS}

As variáveis proxies utilizadas nessa pesquisa estão disponíveis no banco de dados do Worldbank e Transparency International. Como proxy das variáveis de produção e estoque de capital per capita da equação empírica, foram utilizados o produto interno bruto (PIB) per capita e a formação bruta de capital (FBK) a preços constantes dividido pela população nacional do Worldbank. A proxy da variável de estoque de capital humano é a taxa de matrícula no ensino pré-primário, também disponível no banco de dados do Worldbank. A proxy de corrupção é um índice de corrupção percebida (IPC) nos países do mundo disponível no banco de dados da Transparency International. O ICP varia de zero a cem, onde zero representa um país totalmente corrupto e cem um país sem corrupção.

QUADRO 1 - Descrição das variáveis

\begin{tabular}{|c|c|c|c|}
\hline Variável & Descrição das variáveis proxies & Fonte & Período \\
\hline$Y$ & Nível do Produto per capita dos países cuja proxy é PIB per capita a preços \\
constantes & Worldbank & $2012-2017$ \\
\hline$K$ & Estoque de capital per capita dos países cuja proxy é a FBK per capita a preços & Worldbank & $2012-2017$ \\
\hline$H$ & Estoque de capital humano per capita cuja dos países do mundo proxy é a taxa de & Worldbank & $2012-2017$ \\
\hline$I c p$ & Ínatrícula no ensino pré-primário & $\begin{array}{c}\text { Transparency } \\
\text { International }\end{array}$ & $2012-2017$ \\
\hline
\end{tabular}

FONTE: Elaboração própria.

\section{RESULTADOS E DISCUSSÕES}


A estimativa da equação ampliada do modelo de Solow pressupõe a consistência empírica das relações do estoque de capital físico e humano sobre o Produto Interno Bruto per capita (PIBpc). No que tange a esse aspecto da análise, a Figura 2 deixa claro o ajuste das referidas variáveis proxies em relação à produção agregada per capita mundial. A nuvem de dispersão do PIB per capita em relação às proxies da formação bruta de capital per capita e taxa de alfabetização pré-primária se mostram positivamente relacionadas e bastante concentradas em torno da tendência. Entre os países com menor formação de capital e PIBpc estão o Haiti e a República da África Central (Figura 2a). Os países com os piores indicadores de capital humano e PIBpc são Bangladesh, República Democrática do Congo e República Dominicana. Os países com a maior taxa de educação correlacionados ao PIBpc são Mauritânia e Áustria (Figura 2b).
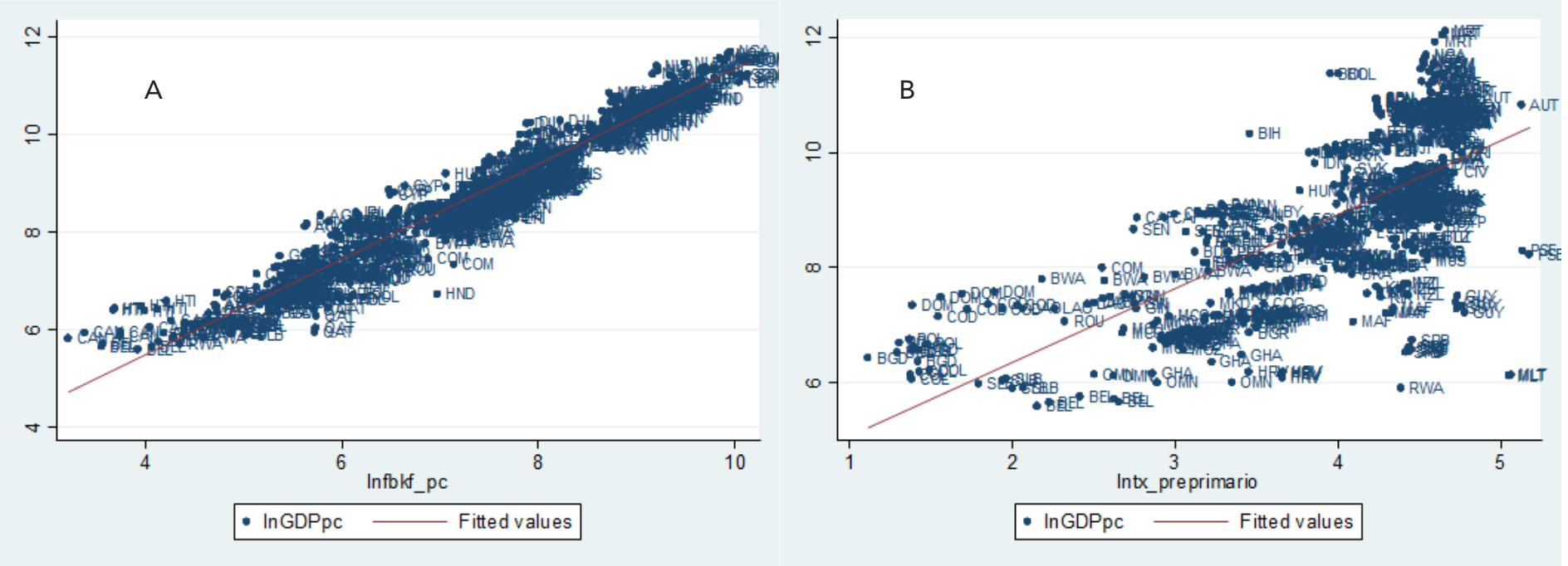

FIGURA 2: Nuvem de dispersão das relações entre o pib per capita e a formação do capital físico (A) e humano (B).

A modelagem assumida do efeito não linear da corrupção sobre o PIB per capita se mostra consistente com base na Figura 3. Mesmo a nuvem de dispersão da relação do PIB per capita com a corrupção exibindo pontos dispersos, a tendência observada é de que a ausência de corrupção exibida pelo Índice de corrupção percebida (IPC) demonstra uma relação positiva e decrescente com a produção agregada mundial. Isso sugere dizer que a percepção de alguma corrupção é preferível à ausência completa dela. Nesse caso, tanto a teoria rente-seeking quanto a teoria revisionista teriam alguma razão sobre os efeitos da corrupção. Contudo, esse resultado pode também estar associado ao sentimento de desconfiança social que 
ocorre logo após períodos de grandes investimentos, como são os exemplos das resseções econômicas que se intercalam com os ciclos expansivos do crescimento econômico. De todo modo, o fato é que o Brasil, Barbados e a Dinamarca aparecem com um índice de ausência de percepção de corrupção maior do que Somália e Libéria, e ainda assim exibem PIB per capita inferior ao dos referidos países (Figura 3a). Afeganistão e Polônia aparecem como exemplos dos piores índices de corrupção e baixa produção agregada. Observando unicamente a linha de tendência da função quadrática extraída da nuvem de dispersão da relação entre a produção agregada per capita e o índice de percepção da corrupção, é possível presumir que existe um nível ótimo de corrupção (Figura 3b).

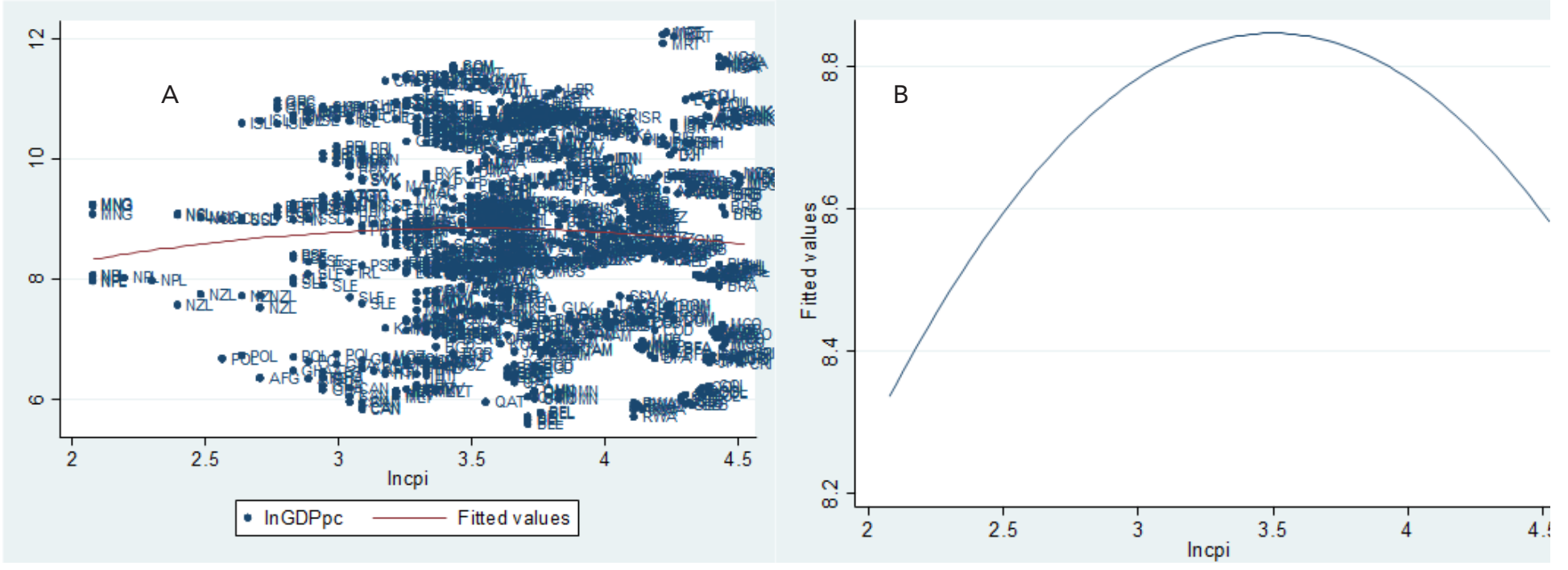

FIGURA 3: Nuvem de dispersão da relação entre o $\operatorname{lnPIBpc}$ e o $\operatorname{lnICP}(\mathrm{A})$ e sua tendência (B)

A estatística descritiva da Tabela 1 apresenta os valores de média geral e desvio padrão da amostra dos países empilhados, desvio padrão entre os países do grupo e dos países ao longo do tempo. Nesses termos, os dados mostram que o PIB per capita mundial $\left(y_{i}\right)$ teve média de US\$ 16.069,58 de 2002 a 2017; dadas as médias de US\$ 3.649,59 com formação de capital fixo per capita $\left(k_{i}\right) ; 64,49 \%$ de taxa de educação $\left(h_{i t}\right)$; e 42.97 de taxa de percepção da corrupção $\left(c_{i t}\right)$. Além disso, é possível esclarecer também que a mudança dos países individualmente ao longo do tempo gerou uma dispersão nas variáveis do modelo bem inferior as diferenças entre os países no mesmo tempo. Esse resultado é esperado uma vez que a heterogeneidade das economias do mundo é grande e o tempo de mudança considerado nessa análise é de apenas cinco 
anos. Portanto, um desvio padrão dentro dos países em cinco anos que superasse a heterogeneidade mundial entre os países, só seria possível através mudanças radicais intangíveis em investimento, educação e confiança institucional em torno da percepção de corrupção.

TABELA 1: Estatística descritiva das variáveis do modelo empírico em US\$

\begin{tabular}{|c|c|c|c|c|c|}
\hline Variáveis & Painel & Média & Desvio-padrão & Mínimo & Máximo \\
\hline \multirow{4}{*}{$y_{i t}$} & Geral & 16069.58 & 22405.57 & 265.2856 & 179308.1 \\
\cline { 2 - 6 } & Entre & & 23812.02 & 294.5468 & 167569.5 \\
\cline { 2 - 6 } & Dentro & & 2427.896 & -2204.249 & 31992.15 \\
\hline \multirow{3}{*}{$k_{i t}$} & Geral & 3649.594 & 4595.93 & 24.87338 & 25223.66 \\
\cline { 2 - 6 } & Entre & & 4525.686 & 44.49611 & 24603.41 \\
\cline { 2 - 6 } & Dentro & & 656.3347 & -1422.085 & 12247.59 \\
\hline \multirow{3}{*}{$h_{i t}$} & Geral & 64.48911 & 32.96573 & 3.05085 & 176.4621 \\
\cline { 2 - 6 } & Entre & & 33.65919 & 3.803918 & 156.9977 \\
\cline { 2 - 6 } & Dentro & & 5.083285 & 6.421126 & 107.9405 \\
\hline \multirow{3}{*}{$c_{i t}$} & Geral & 42.97053 & 19.63904 & 8 & 92 \\
\cline { 2 - 6 } & Entre & & 19.43853 & 8.5 & 90.33333 \\
\cline { 2 - 6 } & Dentro & & 2.190865 & 32.37053 & 52.47053 \\
\hline
\end{tabular}

FONTE: Elaboração própria.

A Tabela 2 apresenta os resultados do modelo empírico proposto de acordo com os métodos de estimação com dados em painel empilhado, com efeito fixo e com efeito aleatório sem e com controle de tendência. Todas as estimativas foram realizadas com desvio-padrão robusto dos parâmetros, inibindo o efeito de problemas associados a heterocedasticidade e autocorrelação serial. Em todos os casos os coeficientes exibem parâmetros estimados com o sinal esperado pela relação teórica, as únicas diferenças se dão em termos de desvio padrão e significancia estatística. Independente da especificação apresentada e do estimador, os resultados demonstram que além dos efeitos do capital fisico e humano sobre o produto per capita, a corrupção exerce um efeito incremental não linear sobre o comportamento do PIB per capita global.

A hipótese assumida de acordo com as teorias rent-seeking e revisionista é de que a corrupção inibe o desempenho da produção agregada, ao mesmo tempo em que estimula os investimentos estruturantes. Em quase todas as especificações os fatores capital físico e humano exibiram significancia estatística a 1\% e 5\%. Contudo, as únicas especificações que exibiram um efeito causal significativo da corrupção sobre a produção agregada per capita foi o OLS com tendência e o estimador de efeito fixo com tendência. A rigor, o estimador OLS com as dummies de tempo e de países corresponde ao estimador de efeito fixo. Todos os coeficientes, desvio padrão e significância estatísticas são iguais em ambos os modelos. 


\section{Revista}

\section{dos Mestrados}

Profissionais

ISSN: 2317-0115

TABELA 2: Estimativas do modelo proposto segundo o método de estimação com painel balanceado

\begin{tabular}{|c|c|c|c|c|c|c|}
\hline Variáveis & OLS & $\begin{array}{l}\text { OLS com } \\
\text { tendencia }\end{array}$ & Efeito fixo & Efeito aleatório & $\begin{array}{c}\text { Efeito fixo com } \\
\text { tendencia }\end{array}$ & $\begin{array}{l}\text { Efeito aleatório } \\
\text { com tendência }\end{array}$ \\
\hline $\operatorname{lnk}$ & $\begin{array}{c}0.9444933^{* * *} \\
(0.0125804)\end{array}$ & $\begin{array}{c}0.3010867^{* * *} \\
(0.0508347)\end{array}$ & $\begin{array}{c}0.2101464^{* * *} \\
(0.0367951)\end{array}$ & $\begin{array}{l}0.792451^{* * *} \\
(0.0436274)\end{array}$ & $\begin{array}{c}0.3010867^{* * *} \\
(0.0662677)\end{array}$ & $\begin{array}{c}0.7739599^{* * *} \\
(0.0444588)\end{array}$ \\
\hline $\operatorname{lnh}$ & $\begin{array}{c}0.1704422^{* * *} \\
(0.0230743)\end{array}$ & $\begin{array}{c}0.1716572^{* * *} \\
(0.0520563)\end{array}$ & $\begin{array}{c}0.0480984 \\
(0.0445858)\end{array}$ & $\begin{array}{c}0.2037552^{* * *} \\
(0.057714)\end{array}$ & $\begin{array}{l}0.1716572^{* *} \\
(0.0691852)\end{array}$ & $\begin{array}{c}0.2925735^{* * *} \\
(0.0595729)\end{array}$ \\
\hline $\ln c$ & $\begin{array}{l}0.4973757^{* *} \\
(0.2410907)\end{array}$ & $\begin{array}{l}0.8095083^{* *} \\
(0.3886891)\end{array}$ & $\begin{array}{c}0.8209079 \\
(0.5249344)\end{array}$ & $\begin{array}{c}0.7175577 \\
(0.6273595)\end{array}$ & $\begin{array}{c}0.8095083^{* *} \\
(0.387479)\end{array}$ & $\begin{array}{c}0.7255463 \\
(0.5232051)\end{array}$ \\
\hline $\ln c^{2}$ & $\begin{array}{l}-0.0530663 \\
(0.0344688)\end{array}$ & $\begin{array}{c}-0.1325036^{* *} \\
(0.0588889)\end{array}$ & $\begin{array}{c}-0.136713^{*} \\
(0.0777531)\end{array}$ & $\begin{array}{l}-0.1001995 \\
(0.0899442)\end{array}$ & $\begin{array}{c}-0.1325036^{* *} \\
(0.0598438) \\
\end{array}$ & $\begin{array}{l}-0.0995319 \\
(0.0751473)\end{array}$ \\
\hline Constante & $\begin{array}{c}0.086425 \\
(0.4292247) \\
\end{array}$ & $\begin{array}{l}4.424141^{* * *} \\
(0.7281279)\end{array}$ & $\begin{array}{c}5.994153^{* * *} \\
(0.954365)\end{array}$ & $\begin{array}{l}0.9122595 \\
(1.013337) \\
\end{array}$ & $\begin{array}{l}4.826572 * * * \\
(0.7362342)\end{array}$ & $\begin{array}{c}0.6987499 \\
(0.8330449)\end{array}$ \\
\hline Paises - & Não & Sim & Sim & Sim & Sim & Sim \\
\hline Anos - & Não & Sim & Não & Não & Sim & Sim \\
\hline $\begin{array}{l}\text { Teste de } \\
\text { Hausman }\end{array}$ & & & & & & \\
\hline$\chi^{2}$ & & & & & \multicolumn{2}{|c|}{407.90} \\
\hline Prob $>\chi^{2}$ & & & & & \multicolumn{2}{|c|}{0.0000} \\
\hline Teste de Chow & & & 44.99 & & & \\
\hline Prob $>F$ & & & 0.0000 & & & \\
\hline $\begin{array}{l}\text { Breusch e } \\
\text { Pagan }\end{array}$ & & & & & & 679.70 \\
\hline Prob $>\chi^{2}$ & & & & & & 0.0000 \\
\hline Wald $\chi^{2}$ & & & & 1259.39 & & 1421.10 \\
\hline Prob $>\chi^{2}$ & & & & 0.0000 & & 0.0000 \\
\hline Teste F & 3057.22 & 1512.47 & 9.88 & & 75.24 & \\
\hline Prob $>$ F & 0.0000 & 0.0000 & 0.0000 & & 0.0000 & \\
\hline $\mathrm{R}^{2}$ & 0.9598 & 0.9981 & 0.0920 & 0.0821 & 0.3394 & 0.2791 \\
\hline
\end{tabular}

FONTE: Elaboração própria 
Nota: ${ }^{* * *}$ significancia a $1 \%,{ }^{* *}$ a $5 \% e^{*}$ a $10 \%$; entre parenteses estão as estimativas de desvio padrão dos parâmetros. A base de dados dessas estimativas é balanceada mas apresenta alguns valores missing. Como medida de robustez da análise as mesmas equações foram estimadas sem valores missing com um painel não balanceado. O exercício gerou os mesmos resultados do painel balanceado.

O estimador de efeito fixo com dummy de tempo se mostra como a especificação mais coerente com a relação empírica assumida devido a um conjunto de testes. Todos os testes de hipótese conjunta de que os parâmetros são iguais a zero são rejeitados a $1 \%$ de significância, conforme as estatísticas dos testes $F$ e Wald. Entres as especificações estimadas com dados empilhados contra o de efeito fixo, o teste de Chow rejeita a hipótese de que estimador OLS é preferível ao modelo com efeito fixo. O mesmo é observado para o teste do modelo OLS em relação ao estimador de efeito aleatório, através do teste Breusch e Pagan. O estimador OLS com dados empilhados se mostra menos consistente do que os modelos com controle de países. Entre os estimadores de efeito fixo e aleatório, o teste de Hausman rejeita a hipótese de que a diferença entre os coeficientes não é sistemática. Por essa razão, não é possível afirmar que o modelo de efeito aletório seja mais consistente que o de efeito fixo. Logo, aceita-se a hipótese alternativa de que existem características não observáveis inerentes aos países, invariantes no tempo, que afetam a produção agregada. Portanto, aceita-se o estimador de efeito fixo.

O referido estimador demonstra que todos os parâmetros estimados são significativos a $5 \%$, e que o efeito não linear da corrupção sobre a produção agregada mundial demonstra a existência de um valor ótimo de corrupção. Esse valor é compatível, em média, com as maiores produções agregadas per capita no mundo. Tomando a derivada parcial da equação estimada em relação ao logaritmo natural da corrupção (lnc) igual a zero, observa-se que quando a taxa de corrupção for de aproximadamente $21.214 \%$, que corresponde a $\exp (\operatorname{lnc}=3,054)$, tem-se o máximo da função de produção. Nesse caso, assumindo por absurdo um mundo com ausência total de corrupção, o PIBpc seria em média inferior. Esse resultado de uma taxa ótima de corrupção sugere que em média alguma corrupção é preferível à ausência absoluta dela. De outro modo, é o mesmo que afirmar que existe uma taxa de corrupção alta o suficiente para estimular a velocidade protocolar dos investimentos, e baixa o suficiente para não afetar a confiança institucional dos investimentos na economia.

Embora esse resultado possa parecer um contrassenso no trade-off eficiência e produção, ele ilustra a proposição da teoria revisionista de que alguma corrupção agiliza os investimentos e portanto o crescimento econômico, sem negar a premissa rent-seeking. Ou ainda, pode estar associada às situações econômicas de recessão intercalada aos ciclos expansivos. Como a proxy de corrupção é definida com base na percepção dos indivíduos, esse sentimento pode ser influenciado pela 
insatisfação social provocada pelas crises econômicas que se dão logo após grandes investimentos estruturantes. A corrupção é uma medida de difícil mensuração devido à natureza dos fatos corruptos, que na maioria das vezes pressupõe uma investigação judicial condicionada a denúncias formais e consistentes.

\section{CONSIDERAÇÕES FINAIS}

Na análise dos efeitos da corrupção sobre a produção agregada mundial assumiu-se como hipóteses três resultados possíveis: o resultado cuja ausência de corrupção aumenta a produção agregada mundial da teoria rent-seeking; o resultado oposto da teoria revisionista; e a hipótese de que essas forças antagônicas estivessem atuando simultaneamente. O teste empírico baseado no modelo de Solow ampliado demonstra que a terceira hipótese é, em média, a mais realista para o universo dos dados. Esse resultado é captado através da relação não linear da corrupção sobre a produção. Identifica-se que, em média, a ausência de corrupção aumenta o Produto Interno Bruto per capita mundial, mas a uma taxa decrescente. Esse fato permite assumir que existe uma taxa ótima de corrupção, confiável o suficiente para atrair novos investimentos e corrupta o suficiente para não gerar entraves protocolares.

Contudo cabe ainda enfatizar que o efeito da corrupção sobre a produção agregada é residual. A importância incremental da variável de corrupção na função de produção do modelo ampliado de Solow é muito pequena, mas ainda assim possui significância estatística. $O$ modelo de Solow ampliado descreve as fontes causais reais da produção real agregada. Nesse contexto, a corrupção, por mais que exerça efeitos sobre a produção real, ela não é mais do que a percepção dos indivíduos em relação a como estão sendo geridas as políticas de investimentos privado e público. Os principais fatores do modelo de Solow ampliado são o capital físico e o capital humano. Esses dois fatores de produção são os principais responsáveis pela explicação da mudança na produção agregada condicionada as variáveis do modelo empírico. 


\section{REFERÊNCIAS}

ABRAMO, Cláudio Weber. Relações entre índices de percepção de corrupção e outros indicadores em onze países da América Latina. SPECK, Bruno W. et al. Os custos da corrupção. Cadernos Adenauer, n. 10, p. 47-62, 2000.

BARDHAN, Pranab. Corruption and development: a review of issues. Journal of economic literature, v. 35, n. 3, p. 1320-1346, 1997.

BOLL, José Luis Serafini. A corrupção governamental no Brasil: construção de indicadores e análise da sua incidência relativa nos estados brasileiros, 2010. 75 f. Dissertação (Mestrado em Economia do Desenvolvimento) - PUCRS. Porto Alegre - RS.

CARRARO, A.; FOCHEZATTO, A.; HILBRECHT, R. O. O impacto da corrupção sobre o crescimento econômico do Brasil: aplicação de um modelo de equilíbrio geral para o período 1994-1998, 2006. XXXIV Encontro Nacional de Economia. Disponível em: < http://www.anpec.org.br/ encontro2006/artigos/Ao6Ao57.pdf $>$ Acesso em: 30 nov. 2017.

CENTRO DE INTEGRIDADE PÚBLICA. Os Custos da Corrupção para a Economia Moçambicana: Por quê é que é importante combater a corrupção num clima de fragilidade fiscal, 2016. Disponível em: $<$ https:// cipmoz.org/wp-content/uploads/2018/o8/CIP-Custos da Corrupcao.pdf $>$ Acesso em: 29 nov. 2017.

CIERCO, Teresa; BELO, António. Is Nigéria a failed state? The Boko Haram group. Revista Brasileira de Ciência Política, n. 21, p. 121-146, 2016.

COMISSÃO EUROPEIA. Dinamarca. Relatório Anticorrupção da UE. Bruxelas. Relatório, 2014.

DEL MONTE, Alfredo; PAPAGNI, Erasmo. Public expenditure, corruption, and economic growth: the case of Italy. European journal of political economy, v. 17, n. 1, p. 1-16, 2001.

DENMARK. The Official Website of Denmark. Disponível em: < http://denmark.dk/en/quick-facts/facts> Acesso em: 05 dez. 2017.

FEDERAÇAO DAS INDÚSTRIAS DO ESTADO DE SAO PAULO (FIESP). Relatório Corrupção: custos econômicos e propostas de combate, 2010. Disponível em: <www.fiesp.com. br/arquivo-download/?id=2021 $>$. Acesso em: 15 Out. 2016.

FIORINO, Nadia; GALLI, Emma; PETRARCA, Ilaria. Corruption and Growth: Evidence from the Italian regions. European 
Journal of Government and Economics, v. 1, n. 2, p. 126-144, 2012.

GARCIA, R. L. A Economia da Corrupção-Teorias e

Evidências - Um aplicação ao setor de obras rodoviárias no Rio Grande do Sul. 361 f. Tese (Doutor em Economia) - Programa de Pós Graduação em Economia da Faculdade de Ciências Econômicas da Universidade Federal do Rio Grande do Sul. Porto Alegre-RS, 2003.

HUNTINGTON, Samuel P. Modernization and corruption. Political Order in Changing Societies. New Haven, Conn: Yale University Press, p. 59-71, 1968.

Instituto de Pesquisa Econômica Aplicada (IPEA). Como funcionam os paraísos fiscais, (2016). Disponível em: $<$ http://desafios.ipea.gov.br/index.php?option=com content\&view $=$ article $\&$ id $=3236 \&$ catid $=30 \&$ Itemid $=41>$ Acesso em: 10 fev. 2018.

LEFF, Nathaniel H. Economic development through bureaucratic corruption. American behavioral scientist, v. 8, n. 3, p. 8-14, 1964.

MANKIW, N. Gregory; ROMER, David; WEIL, David N. A contribution to the empirics of economic growth. The quarterly journal of economics, v. 107, n. 2, p. 407-437, 1992.

$\mathrm{MO}$, Pak Hung. Corruption and economic growth. Journal of comparative economics, v. 29, n. 1, p. 66-79, 2001.

NIGERIA. Federal Republic of Nigeria. Disponível em: $<$ http://www.nigeria.gov.ng/index.php/201604-06-08-38-30> Acesso em: 04 dez. 2017.

NYE, Joseph S. Corruption and political development: A cost-benefit analysis. American political science review, v. 61, n. 2, p. 417-427, 1967.

SHLEIFER, Andrei; VISHNY, Robert W. Corruption. The quarterly journal of economics, v. 108, n. 3, p. 599-617, 1993.

SILVA, Marcos Fernandes Gonçalves da. Economia Política da Corrupção: Um ensaio crítico. EAESP/FGV/ NPP - Núcleo de Pesquisas e Publicações. Relatório de Pesquisa № 3. São Paulo, 1995. Disponível em: $<\underline{\text { http:// }}$ bibliotecadigital.fgv.br/dspace/bitstream/handle/10438/2976/ Relo3-95.pdf?sequence=1> $>$ Acesso em: 26 fev. 2018.

SILVA, Marcos Fernandes Gonçalves da. Corrupção e produção de bens públicos. In: BIDERMAN, Ciro; ARVATE, Paulo Roberto (Org.). Economia do setor público no Brasil. Rio de Janeiro: Elsevier 1o $0^{\underline{a}}$ reimpressão. p. 126-135, 2004. 
SOBRAL, Eryka Fernanda Miranda; FERREIRA, Monaliza de Oliveira; BESARRIA, Cassio de Nobrega. Corrupção e os seus efeitos sobre a dinâmica do crescimento econômico regional: uma análise do caso brasileiro. In: $43^{\circ}$ Encontro Nacional de Economia (ANPEC), 2015, Florianópolis - SC. Anais... Florianopolis-SC: ANPEC, 2015. Disponível em: < https:// www.anpec.org.br/encontro/2015/submissao/files_I/i6-491dee 12742cac2c962bafbecf2d12aa.pdf $>$ Acesso em: 24 ago. 2017.

SOBRAL, Eryka Fernanda Miranda. Corrupção e os seus efeitos sobre a dinâmica do crescimento econômico regional: uma análise do caso brasileiro. 2014. 56 f. Dissertação (Mestrado em Economia) - Programa de Pós-Graduação em Economia da Universidade Federal de Pernambuco. Caruaru - PE, 2014.

Transparência na Gestão Pública - Controle Cidadão. A corrupção no Brasil e no Mundo. Fortaleza - CE. Edições Demócrito Rocha/UANE/Instituto Albanisa Sarasate, v. 1, 2016.

TRANSPARENCY INTERNATIONAL. Disponível em: <https://www.transparency.org/> Acesso em: 15 nov. 2017.

WORLD DATA BANK. Disponível em: <http://data. worldbank.org/> Acesso em: 18 nov. 2017.

WORLDWIDE GOVERNANCE INDICATORS (WGI). Disponível em: <http://info.worldbank.org/ governance/wgi/\#home> Acesso em: 25 nov. 2017. 